EESTI NSV TEADUSTE AKADEEMIA TOIMETISED, 22. KOIDE KEEMIA * GEOLOOGIA, 1973, NR, 3

ИЗВЕСТИЯ АКАДЕМИИ НАУК ЭСТОНСКОЙ ССР. ТОМ 22 ХИМИЯ * ГЕОЛОГИЯ. 1973, № 3

\title{
КИНЕТИКА РЕАКЦИИ ДИСПРОПОРЦИОНИРОВАНИЯ 2-ФЕНИЛБУТАНА
}

Синтез алкилфенилэтанолов путем присоединения окиси этилена к фенилалканам при избытке хлористого алюминия сопровождается параллельным диспропорционированием фенилалканов. В результате этой побочной реакции в реакционной смеси появляются диалкилбензолы, из которых получаются нежелательные диалкилфенилэтанолы. Методика синтеза и описание установки приведены в сообщениях $[1,2]$.

При синтезе алкилфенилэтанолов с короткой боковой алкильной шепью $\left(\mathrm{C}_{2}\right)$ относительная реакционная способность диалкилбензолов по Ингольлу выше. чем моноалкилбензолов. С удлинением алкильной цепи реакшионная способность диалкилбензолов снижается и в реакционной смеси появляются углеводороды, выкипаюшие в тех же температурных интепвалах. что и шелевые спипты. Для получения спиртов, не загрязненных vглеволоподами, оксиэтилирование необходимо вести в условиях, исключаюших или снижающих до минимума реакцию диспропорционипования фенилалканов.

Пепвым этапом в решении этого вопроса является определение констант скоппстей пеакшии дисппопопшионирования.

Дисппопопионипование 2-фенилбутана изучалось при молярном соотношении 2-фенилбутан - хлористый алюминий, равном $3 ; 1$. Такое соптношение реагентов приблизительно имитирует условия оксиэтилиров ния фенилалканов. Для определения состава реакционной смеси в данный момент времени использовали специальную методику торможения реакции в отобранной пробе [ $\left.{ }^{1}\right]$. Определение констант скоростей при разных температурах процесса позволяет вычислить температурный коэффициент реакции и определить тем самым оптимальные условия синтеза алкилфенилэтиловых спиртов с наименьшим количеством диалкилбензолов.

Кинетические показатели диспропорционирования 2-фенилбутана при $+6{ }^{\circ} \mathrm{C}$ в различные периоды реакции приведены в табл. 1 и 2 , а также графически изображены на рис. 1 и 2 . Зависимость логарифма концентрации от времени имеет различный характер. В начале реакции диспропорционирования фенилалканов зависимость имеет прямолинейный характер (рис. 1 , прямая $Б$ ) и выражается $\lg \left(C-C_{\infty}\right)=f(\tau)$, где $C-$ экспериментально найденная концентрация 2-фенилбутана, а $C_{\infty}-$ равновесная концентрация. При диспропорционировании 2-фенилбутана в начале реакции, примерно до концентрации 70 моль\%, образуется главным образом дибутилбензол и реакция удовлетворяет уравнению первого порядка. 


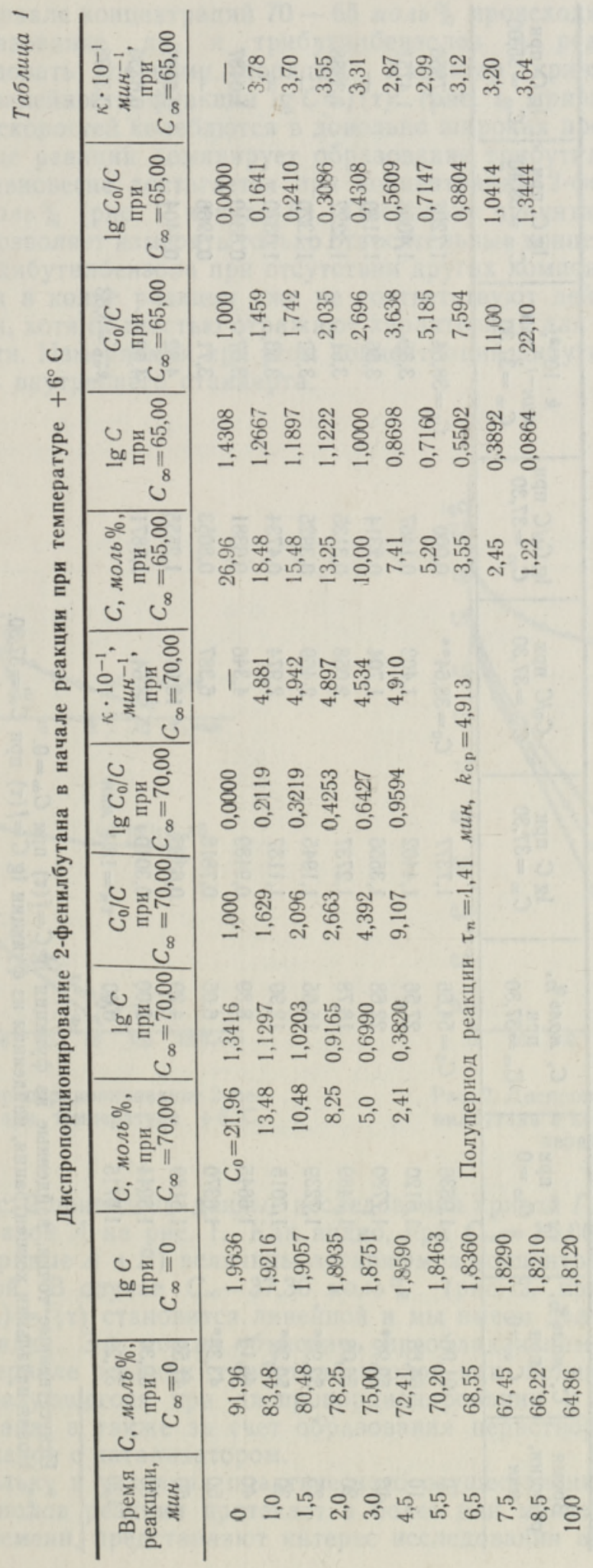




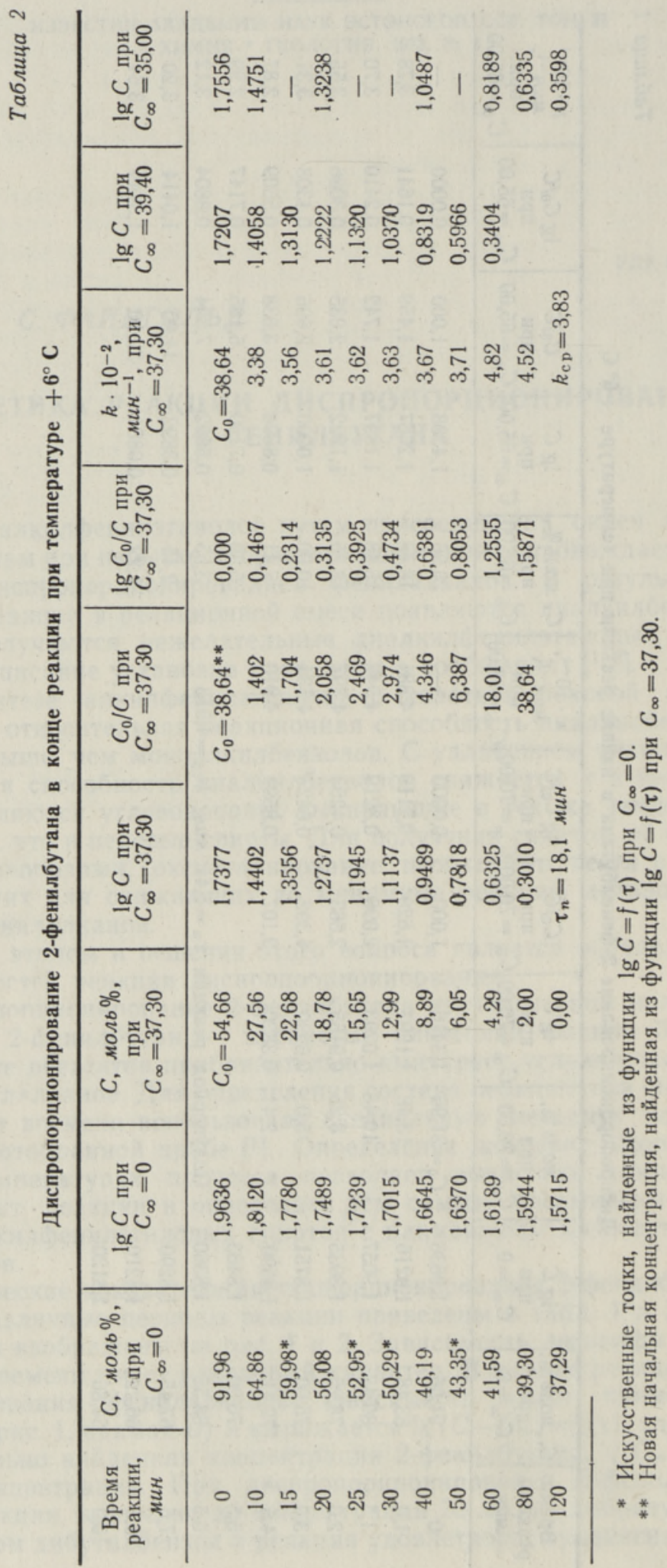


В интервале концентраций $70-65$ моль\% происходит последовательное образование ди- и трибутилбензолов и реакция перестает соответствовать первому порядку. Характер кривых меняется и не дает линейности функции $\lg C=f(\tau)$ (рис. 1 , кривая $A$ ). Величины констант скоростей колеблются в довольно широких пределах.

В конце реакции доминирует образование трибутилбензола и полимеров. Равновесие достигается при концентрации 2-фенилбутана $C_{\infty}=$ $=37,30$ моль \% (рис. 1 , кривая $B$ ). Поскольку принятая нами методика анализа позволяет измерять только относительные концентрации 2-фенилбутана и дибутилбензола при отсутствии других компонентов, то данные измерения в конце реакции уже не соответствуют действительной концентрации, хотя полностью отражают характерные для него общие закономерности. Измеряемая при этом концентрация дибутилбензола выполняет роль внутреннего стандарта.

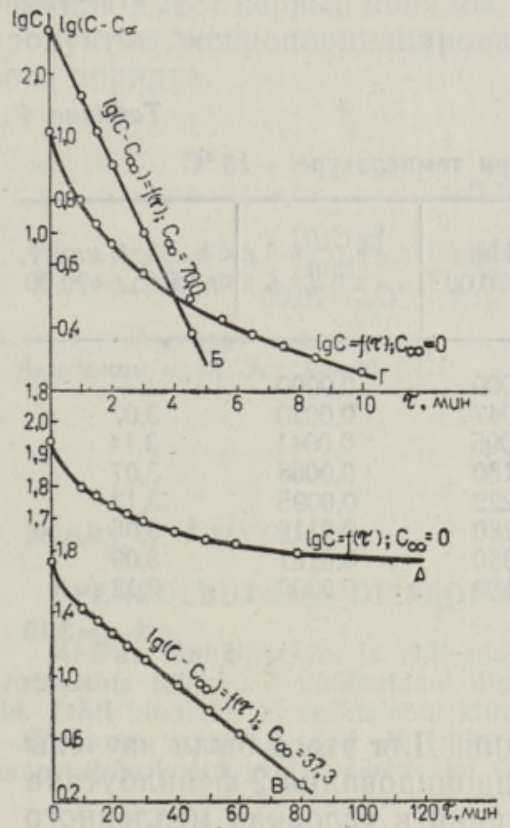

Рис. 1. Диспропорционирование 2-фенилбутана при температуре $+6{ }^{\circ} \mathrm{C}$.

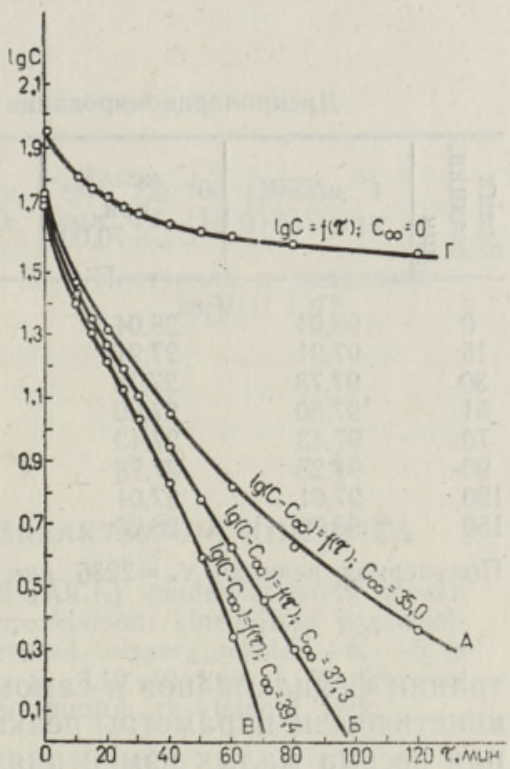

Рис. 2. Диспропорционирование 2-фенилбутана в конце реакции при тем. пературе $+6{ }^{\circ} \mathrm{C}$.

На рис. 2 приведены данные исследования кривой $\Gamma$, которая соответствует кривой $A$ на рис. 1. Как видно, при $C_{\infty}=35,00$ и 39,40 моль $\%$ (рис. 2, кривые $A$ и $B$ ) величины логарифмов концентраций отклоняются от прямой. В случае $C_{\infty}=37,30$ моль $\%$ (рис. 2 , кривая $Б$ ) функция $\lg \left(C-C_{\infty}\right)=f(\tau)$ становится линейной и мы имеем дело с реакцией первого порядка. Это можно объяснить преобладающим образованием в этом интервале реакции трибутилбензолов или полимеризацией бутилена, образующегося при диспропорционировании и деалкилировании фенилбутана, а также за счет образования нерастворимого комплекса фенилалканов с катализатором.

Поскольку в условиях практического осуществления синтеза алкилфенилэтанолов реакция протекает в более или менее короткие промежутки времени, представляют интерес исследования изменения концен- 
Диспропорционирование 2-фенилбутана при температуре $-5^{\circ} \mathrm{C}$

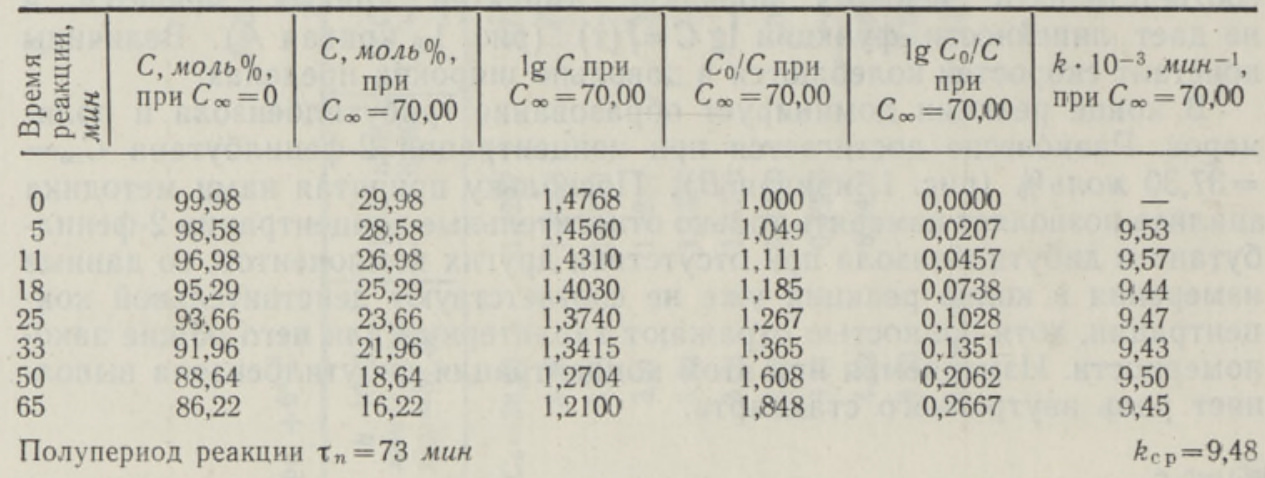

Таблица 4

Диспропорционирование 2-фенилбутана при температуре $-15{ }^{\circ} \mathrm{C}$

\begin{tabular}{|c|c|c|c|c|c|c|}
\hline 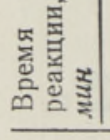 & $\begin{array}{l}C, \text { моль } \% \text {, } \\
\text { при } C_{\infty}=0\end{array}$ & $\begin{array}{c}C, \text { моль } \%, \\
\text { при } \\
C_{\infty}=70,00\end{array}$ & $\begin{array}{c}\lg C \text { при } \\
C_{\infty}=70,00\end{array}$ & $\begin{array}{c}C_{0} / C_{\text {при }} \\
C_{\infty}=70,00\end{array}$ & $\begin{array}{c}\lg C_{0} / C \\
\text { при } \\
C_{\infty}=70,00\end{array}$ & $\begin{array}{l}k \cdot 10^{-4}, \text { мин }^{-1} \\
\text { при } C_{\infty}=70,00\end{array}$ \\
\hline $\begin{array}{r}0 \\
15 \\
30 \\
51 \\
70 \\
90 \\
120 \\
150\end{array}$ & $\begin{array}{l}98,04 \\
97,91 \\
97,78 \\
97,60 \\
97,43 \\
97,28 \\
97,01 \\
96,76\end{array}$ & $\begin{array}{l}28,04 \\
27,91 \\
27,78 \\
27,60 \\
27,43 \\
27,28 \\
27,01 \\
26,76\end{array}$ & $\begin{array}{l}1,4478 \\
1,4458 \\
1,4438 \\
1,4409 \\
1,4383 \\
1,4359 \\
1,4316 \\
1,4275\end{array}$ & $\begin{array}{l}1,0000 \\
1,0047 \\
1,0095 \\
1,0160 \\
1,0222 \\
1,0280 \\
1,0380 \\
1,0480\end{array}$ & $\begin{array}{l}0,0000 \\
0,0020 \\
0,0041 \\
0,0068 \\
0,0095 \\
0,0119 \\
0,0161 \\
0,0203\end{array}$ & $\begin{array}{l}3,07 \\
3,14 \\
3,07 \\
3,13 \\
3,05 \\
3,09 \\
3,12\end{array}$ \\
\hline Полу & д реак & $\tau_{n}=2236$ & & & & $k_{\mathrm{cp}}=3,10$ \\
\hline
\end{tabular}

трации фенилалканов в самом начале реакции. Для этого были изучены кинетические параметры реакции диспропорционирования 2-фенилбутана при весьма малых изменениях его концентрации в условиях медленного протекания процесса при минусовых температурах. Анализом приведенных выше данных установлено, что изменение концентраций 2-фенилбутана при реакции диспропорционирования находится в интервале от 100 до 70 молярных процентов.

Результаты исследований скорости реакции диспропорционирования 2 -фенилбутана при -5 и $-15^{\circ}$ приведены в табл. 3 и 4 . Газохроматографическим анализом установлено, что реакционная смесь содержит только 2-фенилбутан и дибутилбензол.

Температурный коэффициент реакции в этих условиях составляет около 30 ед. Контрольные вычисления температурного коэффициента непосредственно на основе хроматографических пиков дали примерно те же результаты.

Сравнивая эти данные с результатами изучения кинетики диспропорционирования этилбензола в тех же условиях [2], можно прийти к выводу, что наряду с избытком катализатора на температурный коэффициент влияет и длина боковой цепи фенилалкана. С удлинением боковой цепн фенилалканов от этила к бутилу температурный коэффициент увеличивается. 


\section{Выводы}

1. Определены кинетические показатели побочной реакции диспропорционирования 2-фенилбутана, сопровождающей основную реакцию присоединения окиси этилена к 2-фенилбутану при получении бутилфенилэтилового спирта.

2. Константа скорости диспропорционирования 2-фенилбутана при +6 (средняя), -5 и $-10^{\circ}$ составляет соответственно $4,91 \cdot 10^{-1}, 9,48 \cdot 10^{-3}$ и $3.10 \cdot 10^{-4} \mathrm{Muн}^{-1}$.

3. Температурный коэффициент реакции диспропорционирования бутилбензола составляет до 30 ед.

4. Порядок реакции диспропорционирования бутилбензола изменяется на различных стадиях протекания основной реакции. Вначале эта реакция имеет первый порядок. По мере накопления в реакционной смеси продуктов диспропорционирования реакция переходит в категорию дробного порядка.

\section{Л И T Е Р А У P A}

1. Й ерс Я., Ф айнгольд С., Изв. АН ЭССР, Хим. Геол., 22, 108 (1973).

2. Й ер с Я., Ф ай н гольд С., Изв. АН ЭССР, Хим. Геол., 22, 113 (1973).

Институт химии
Академии наук Эстонской ССР
Поступила в редакцию 28/VIII 1972

\section{J. JOERS, S. FAINGOLD}

\section{2-FENUULBUTAANI DISPROPORTSIONEERUMISREAKTSIOONI KINEETIKA}

Määrati fenüülbutaani ja etüleenoksiidi katalüütilisel $\left(\mathrm{AlCl}_{3}\right)$ kondensatsioonil kōrvalprotsessina toimuva fenüülbutaani disproportsioneerumisreaktsiooni kineetilised parameetrid. Tehti kindlaks, et reaktsiooni kiiruskonstantide väärtused temperatuuridel $+6,-5$ ja $-15^{\circ} \mathrm{C}$ on vastavalt $4,91 \cdot 10^{-1} \mathrm{~min}^{-1}, 9,48 \cdot 10^{-3} \mathrm{~min}^{-1}$ ja $3,10 \cdot 10^{-4} \mathrm{~min}^{-1}$. Reaktsiooni temperatuurikoefitsiendi väärtus on 30 . Protsessi kestel muutub reaktsiooni järk.

\section{J. JOERS, S. FAINGOLD}

\section{THE KINETICS OF THE DISPROPORTIONATION OF 2-PHENYL BUTANE}

Kinetic indices of the disproportionation of phenyl butane as by-reaction upon catalytical $\left(\mathrm{AlCl}_{3}\right)$ condensation of oxyethylene and phenyl butane have been determined. The speed constants at the temperatures $+6,-5$ and $-15^{\circ} \mathrm{C}$ were respectively $4.91 \cdot 10^{-1} \mathrm{~min}^{-1}, 9.48 \cdot 10^{-3} \mathrm{~min}^{-1}$ and $3.10 \cdot 10^{-4} \mathrm{~min}^{-1}$. The temperature coefficient is 30 . The order of the reaction changes during the process. 